\title{
In Vitro Anti-inflammatory and Antimicrobial Activities of Azithromycin After Loaded in Chitosan- and Tween 20-Based Oil-in-Water Macroemulsion for Acne Management
}

\author{
Tamilvanan Shunmugaperumal $^{1,2}$ and Varinder Kaur ${ }^{1}$
}

\begin{abstract}
Received 27 March 2015; accepted 19 August 2015; published online 28 August 2015
Abstract. The objectives of the current investigation are (1) to prepare and characterize (particle size, surface charge (potential zeta), surface morphology by transmission electron microscopy, drug content, and drug release) the azithromycin (AZM, $100 \mathrm{mg}$ )-loaded oil-in-water (o/w) macroemulsion, (2) to assess the toxicity of macroemulsion with or without AZM using RBC lysis test in comparison with AZM in phosphate buffer solution of $\mathrm{pH} 7.4$, (3) to compare the in vitro antimicrobial activity (in Escherichia coli using zone inhibition assay) of AZM-loaded macroemulsion with its aqueous solution, and (4) to assess the in vitro anti-inflammatory effect (using egg albumin denaturation bioassay) of the AZM-loaded macroemulsion in comparison with diclofenac sodium in phosphate buffer solution of $\mathrm{pH}$ 7.4. The AZM-loaded macroemulsion possessed the dispersed oil droplets with a mean diameter value of $52.40 \pm$ $1.55 \mu \mathrm{m}$. A reversal in the zeta potential value from negative $(-2.16 \pm 0.75 \mathrm{mV})$ to positive $(+6.52 \pm$ $0.96 \mathrm{mV}$ ) was noticed when AZM was added into the macroemulsion. At a 1:5 dilution ratio, $2.06 \pm$ $0.03 \mathrm{mg}$ of drug was released from macroemulsion followed by $1.01 \pm 0.01$ and $0.25 \pm 0.08 \mathrm{mg}$, respectively, for 1:10 and 1:40 dilution ratios. Antimicrobial activity maintenance and significant reduction of RBC lysis property were noticed for AZM after loaded in the macroemulsion. However, an increment in the absorbance values for emulsion-treated samples in comparison to the control samples was noticed in the anti-inflammatory test. This speculates the potential of the AZM-loaded emulsion to manage inflammatory conditions produced at Acne vulgaris.
\end{abstract}

KEY WORDS: Acne vulgaris; inflammation; nano- vs. macroemulsion; protein denaturation bioassay; RBC breakdown.

\section{INTRODUCTION}

Acne vulgaris (simply acne) is a multifactorial disease that affects almost $>80 \%$ of people and it comprises lesions of various skin morphologies, ranging from comedones, papules, and pustules to nodules and cysts (1). Its pathophysiology centers on the interplay of hyperkeratinization in pilosebaceous follicles, colonization with the anaerobic diphtheroid, notably Propionibacterium acnes, increased sebum production, and inflammation $(2,3)$. Furthermore, current theories on the pathophysiology of acne hold that the inflammation of acne is due, in part, to an immune reaction to the bacterium or to extracellular products produced in response to the presence of the bacterium, rather than being due to presence of the bacterium itself (4). This indicates that treatments which are aimed solely at reduction in numbers of $P$. acnes organisms are generally not very effective in long-term management of acne. Hence, the acne armamentarium contains many different

\footnotetext{
$\overline{{ }^{1} \text { Department of Pharmaceutical Sciences, Lovely Professional }}$ University, Jalandhar-Delhi, G.T. Road (NH-1), Phagwara, Jalandhar, Punjab, India144411.

${ }^{2}$ To whom correspondence should be addressed. (e-mail: tamilvanan2k@yahoo.com)
}

therapeutic options, including topical benzoyl peroxide, topical and oral antibiotics, topical and oral retinoids, and hormonal agents $(2,5)$. However, topical treatment with antibiotic alone (6) or in combination with other antiacne agents remains as the first-line therapy to manage mild and moderate acne (7). Furthermore, given the multifactorial pathogenesis of acne and the hurdles of adherence to treatment, it becomes always necessary to develop topically applied combination acne products blended with some innovative concept.

The use of oil-in-water $(\mathrm{o} / \mathrm{w})$ nanosized emulsions (with mean particle sizes ranging from 150 to $450 \mathrm{~nm}$ ) having inherent antimicrobial and/ anti-inflammatory properties (8-12) to combat the antibiotic-resistant bacteria is a well-established strategy. Unlike that of antibiotics, the antimicrobial activity of nanosized emulsions is non-specific, thus allowing broadspectrum activity while limiting the capacity for the generation of resistant bacterial strains (8). These features make nanosized emulsion a suitable candidate for wound treatment (10). In addition, incorporating the antibiotic molecule or antiacne agent into the emulsion having inherent antimicrobial activity should ideally produce a synergistic therapeutic efficacy for the efficient management of acne conditions. However, the current report explores the preparation of $\mathrm{o} / \mathrm{w}$ macroemulsion (with mean particle sizes ranging from 1 to 
$75 \mu \mathrm{m}$ ) using a polycationic polysaccharide biopolymer and non-ionic emulgator combination that possesses inherent antiacne, antimicrobial, anti-inflammatory, immunological, and wound healing accelerant properties, and this macroemulsion is also incorporated with an antibiotic molecule. Azithromycin is selected as model antibiotic molecule while chitosan and Tween 20 are used as polycationic biopolymer and non-ionic emulgent molecules to make the o/w macroemulsion.

The objectives of the current investigation are, therefore, (1) to prepare and characterize (particle size, surface charge (potential zeta), surface morphology by transmission electron microscopy, drug content, and drug release) the azithromycin (AZM, $100 \mathrm{mg}$ )-loaded o/w macroemulsion, (2) to assess the toxicity of macroemulsion with or without AZM using RBC lysis (hemolysis) test in comparison with AZM in phosphate buffer solution of $\mathrm{pH} \mathrm{7.4,} \mathrm{(3)} \mathrm{to} \mathrm{compare} \mathrm{the} \mathrm{in} \mathrm{vitro} \mathrm{antimi-}$ crobial activity (in Escherichia coli using zone inhibition assay) of AZM-loaded macroemulsion with its aqueous solution, and (4) to assess the in vitro anti-inflammatory effect (using egg albumin denaturation bioassay) of the AZM-loaded macroemulsion in comparison with diclofenac sodium in phosphate buffer solution of $\mathrm{pH} 7.4$.

\section{MATERIALS AND METHODS}

\section{Materials}

Azithromycin dehydrate was a gift sample from Ranbaxy Laboratories, Gurgaon, India. Castor oil and coconut oil were purchased from S.K. Oil Industries, Jalgaon, Maharashtra, India. Chitosan (molecular weight, $22 \mathrm{kDa}$; deacetylation degree of $\sim 81 \%$ ) and Tween 20 were obtained from SigmaAldrich Chemicals Co., St. Louis, MO, USA. Potassium dihydrogen orthophosphate was purchased from CDH Pvt. Ltd. Laboratories, Mumbai, India. All other chemicals used were of analytical grade and used as received.

\section{Methods}

\section{Formulation Development}

AZM-loaded macroemulsion was prepared with a slight modification according to the method described elsewhere (13). In brief, oil phase containing castor and coconut oils (1:1) and drug (100 mg) were taken in a beaker and heated up to $70^{\circ} \mathrm{C}$. Chitosan $(50 \mathrm{mg})$ was dissolved in $0.05 \mathrm{M}$ of acetic acid and heated up to $70^{\circ} \mathrm{C}$. Water phase containing Tween 20 $(1500 \mathrm{mg})$, glycerin $(1.25 \mathrm{ml})$, and distilled water (to $50 \mathrm{ml}$ ) was taken in a separate beaker and heated up to $70^{\circ} \mathrm{C}$. The oil phase was mixed initially with the chitosan solution and then the water phase was added and stirred well by means of a magnetic stirrer while further heated to a temperature of $85^{\circ} \mathrm{C}$. At this temperature, the obtained crude emulsion was subjected to a droplet size reduction by means of ultrasonication (LOBA CHEMIE, Mumbai, India) for $5 \mathrm{~min}$ and rapidly cools to room temperature. The emulsion was packed in siliconized glass bottles. Three replicate emulsion samples were prepared freshly and were used for further analyses as described below. In addition, AZM solution $(0.1 \% \mathrm{w} / \mathrm{v})$ was prepared using a phosphate buffer saline
(PBS) solution of $\mathrm{pH} 7.4$ and the AZM solution in PBS was the control.

\section{Particle Size Analysis}

The mean droplet diameter was determined utilizing a Malvern Mastersizer (Malvern Instrument Ltd, Malvern, UK) at $25^{\circ} \mathrm{C}$. A laser beam of He-Ne light source at $633-\mathrm{nm}$ wavelength was used. The sensitivity range was $0.02-2000 \mu \mathrm{m}$. About 100-200 $\mu \mathrm{l}$ of emulsion was mixed with $150 \mathrm{ml}$ of dispersing water (Hydro S) before making the measurement. Values reported were the mean droplet diameter of triplicate emulsion samples.

\section{Zeta Potential, pH, and Viscosity Measurements}

The zeta potential measurements were carried out using the Malvern Zetasizer 3000 (Malvern Instruments, Ltd, Malvern, UK). The samples were diluted in double distilled water and the measurements were carried out in $10 \mathrm{mM} \mathrm{NaCl}$ solution. Each sample was analyzed twice, and each analysis consisting of three replicates. The $\mathrm{pH}$ was recorded at given time intervals using a $\mathrm{pH}$ meter under the identical storage temperatures (MP220 pH meter, Mettler Toledo, UK). An Ubbelohde capillary viscometer (Schott, Hofheim, Germany) was used to measure the viscosity of the emulsion samples.

\section{Transmission Electron Microscopy}

In order to evaluate the emulsification efficiency of the two different size reduction steps (initial mixing of oil and water phases by mechanical stirrer followed by high-speed mixing by an ultrasonicator) used during the preparation process, the freshly prepared AZM-loaded emulsion was studied using a transmission electron microscope (CM 12, Philips, Eindhoven, The Netherlands). A drop of diluted emulsion (1:5 dilution with double distilled water (DDW)) was placed on a carbon-coated copper grid and underwent a negative staining technique using $1 \%$ solution of phosphotungstic acid (PTA) sodium salt at $\mathrm{pH}$ 7.4. The excess emulsion was sipped by the filter paper and then air dried at room temperature before being observed under transmission electron microscopy (TEM).

\section{Quantitative Drug Analysis}

AZM content was analyzed using a HPLC system. In the present study, the already reported method (14) was fully validated and was adapted to meet the requirements for the AZM stability-indicating test. In brief, a reversed-phase $250 \times$ 4.6-mm Luna ${ }^{\mathrm{TM}} \mathrm{C}_{18}(5 \mu \mathrm{m})$ column furnished by Phenomenex ${ }^{\mathrm{TM}}$ (USA) and a $2 \times 8-\mathrm{mm}$ precolumn of the same material were used. The mobile phase, at $1 \mathrm{ml} / \mathrm{min}$ flow rate, consisted of a mixture $(15: 47, v / v)$ of acetonitrile and potassium dihydrogen phosphate buffer $(0.067 \mathrm{~mol} / \mathrm{l})$ at $\mathrm{pH} 4.0$, which was adjusted with phosphoric acid. AZM was monitored with a UV-visible absorbance detector at $210 \mathrm{~nm}$ (Kontron HPLC system, Kontron Instruments, Zurich, Switzerland). Six standard solutions of drug in acetonitrile were first prepared and appropriately diluted with acetonitrile to final AZM concentrations ranging from 12.5 (minimum 
detectable concentration) to $2000 \mu \mathrm{g} / \mathrm{ml}$. The AZM-loaded emulsions were directly dissolved in acetonitrile to appropriate dilutions (1: 10-1: 100); AZM was monitored with a UVvisible absorbance detector at $210 \mathrm{~nm}$; under these experimental conditions, the run time was $7.2 \mathrm{~min}$. All the experiments were duplicated and the deviation ranged from 0 to $3 \%$, indicating that the various experimental conditions were well controlled.

\section{Entrapment Efficiency}

The entrapment efficiency (EE) of the emulsions was determined by measuring the concentration of AZM in the aqueous layer obtained by ultracentrifugation (UC) (15). Centrifugation was carried out using a HITACHI ultracentrifugation apparatus, operated at 50,000 $\mathrm{rpm}(\sim 162,000 \times \mathrm{g})$ at $4^{\circ} \mathrm{C}$ for $2 \mathrm{~h}$. Polyallomer tubes were used and their bottoms were pricked with a syringe needle after centrifugation to collect the aqueous phase. Concentrations of AZM in both the aqueous layer and the whole emulsion were determined by HPLC. The EE was calculated according to the following equation (16):

$\mathrm{EE}(\%)=\frac{\left\{\left(C_{\text {total }} \times V_{\text {total }}\right)-\left(C_{\text {water }} \times V_{\text {water }}\right)\right\}}{C_{\text {total }} \times V_{\text {total }}} \times 100$

Where $C_{\text {total }}$ is the AZM concentration in whole emulsion, $V_{\text {total }}$ is the volume of emulsion prepared, $C_{\text {water }}$ is the AZM concentration in the water/aqueous phase, and $V_{\text {water }}$ is the volume of water phase collected after centrifugation.

\section{Thermodegradation Experiment}

About $500 \mu \mathrm{l}$ of AZM-loaded emulsion (equivalent to $1000 \mu \mathrm{g}$ of $\mathrm{AZM}$ ) was taken in a vial, and $50 \mathrm{ml}$ of $\mathrm{pH} 7.4$ phosphate buffer was added into it. In another vial, $1 \mathrm{ml}$ of AZM solution $(1 \mathrm{mg} / \mathrm{ml})$ in $\mathrm{pH} 7.4$ phosphate buffer was taken and diluted with $50 \mathrm{ml}$ buffer. These two vials were kept in (1) an autoclave at $121^{\circ} \mathrm{C}$ and $15 \mathrm{lb} /$ in pressure for $15 \mathrm{~min}$, (2) a hot air oven at $70^{\circ} \mathrm{C}$ for $30 \mathrm{~min}$, and (3) a room temperature at $25^{\circ} \mathrm{C}$ for $30 \mathrm{~min}$. The drug leakage (in percentage) from both emulsion and solution at these three different storage conditions were calculated according to the following formula.

Drug leakage $\%=\frac{\text { Drug amount leached }}{\text { Initial drug amount added }} \times 100$

\section{In Vitro Dissolution}

A membrane free dissolution model as shown previously for o/w nanosized emulsion (17) was adopted in the current investigation in order to study the in vitro release of AZM from o/w macroemulsion. The in vitro release studies were performed in a water bath maintained at $37^{\circ} \mathrm{C}$ using $3 \times 50-\mathrm{ml}$ vials in which $8 \mathrm{ml}$ of DDW was served as medium; 1600, 800, and $200 \mu \mathrm{l}$ of emulsion (entrapping 3.2, 1.6, and $0.4 \mathrm{mg}$ of drug) were added to the first, second, and third vials, respectively, to denote/ represent the corresponding dilution ratios of 1:5, 1:10, and 1:40. Periodically, $500 \mu \mathrm{l}$ of sample was withdrawn from each vials at a time interval of $1,5,10,15$, and 20 min with replenishment using $500 \mu \mathrm{l}$ fresh DDW. The withdrawn samples were analyzed using the validated HPLC method to calculate the amount AZM released from macroemulsion on these three different dilution ratios. The actual amount of AZM released was calculated using the following formula:

AZM amount released $=($ Drug amount present at each of the dilution ratio $)-($ Mean drug amount released at particular time point over 20 min $)$

\section{In Vitro Hemolysis Test}

A normal healthy human volunteer was given a written consent to donate blood for this test. Freshly collected blood from the healthy human volunteer was mixed with an anticoagulant solution $(74.88 \mathrm{mM}$ sodium citrate $v / v)$ and centrifuged at $650 \times g$ for $10 \mathrm{~min}$. The supernatant was discarded and the erythrocytes were resuspended in PBS $(5 \mathrm{mM}$ phosphate, $150 \mathrm{mM} \mathrm{NaCl}, \mathrm{pH}=7.4)$. Next, the erythrocytes were washed three times with an isotonic buffer (PBS), and the upper phase with a buffy coat containing precipitated debris and serum proteins was carefully removed at each wash step. After the last washing, the packed cells were suspended in a buffer to a hematocrit of $50 \%$. All the erythrocyte suspensions used in the experiments were prepared daily. To determine the hemolytic effect, $100 \mu \mathrm{l}$ of each emulsion containing $1000 \mu \mathrm{g}$ of AZM was diluted with $10 \mathrm{ml}$ of PBS, and $1 \mathrm{ml}$ from this diluted emulsion (containing $100 \mu \mathrm{g}$ of AZM) was added to $20 \mu \mathrm{l}$ of erythrocyte suspension (50\% hematocrit) and adjusted to a 4-ml volume with PBS. The samples were stirred and incubated for $30 \mathrm{~min}$ at $37^{\circ} \mathrm{C}$. Debris and intact erythrocytes were removed by centrifugation at $650 \times \mathrm{g}$ for $10 \mathrm{~min}$. The hemoglobin released into the supernatant was detected spectrophotometrically at $540 \mathrm{~nm}$ against a corresponding blank sample. The hemolytic effect, measured as the percentage of hemolysis $(H)$, was determined on the basis of released hemoglobin, according to the following formula (18)

$H(\%)=\frac{A s-A c_{1}}{A c_{2}-A c_{1}} \times 100$

where $A$ is the absorbance, $s$ is for the sample, $c_{1}$ is for the mechanical hemolysis (erythrocytes in PBS), and $c_{2}$ is for $100 \%$ hemolysis (erythrocytes in double distilled water). Control emulsions were prepared under identical experimental conditions, but without AZM, and were tested for hemolysis. 


\section{In Vitro Anti-inflammatory Experiment}

To study the effect of $\mathrm{o} / \mathrm{w}$ macroemulsion on the antiinflammatory activity of AZM, an in vitro anti-inflammatory activity as shown previously for plant extracts by Chandra et al. (19) was adopted with a slight modification in the current investigation. In brief, the AZM (100 mg)-loaded macroemulsion $(50 \mathrm{ml})$ was prepared freshly and $1000-5000 \mu \mathrm{l}$ of emulsion (equivalent to 2000-10,000 $\mu \mathrm{g}$ AZM) was mixed individually with $100 \mathrm{ml}$ of $\mathrm{pH} 7.4$ phosphate buffer. From these, $2000 \mu \mathrm{l}$ (equivalent to 40-200 $\mu \mathrm{g}$ of AZM) was mixed individually with $200 \mu \mathrm{g}$ of egg albumin powder and $2800 \mu \mathrm{l}$ of $\mathrm{pH} 7.4$ phosphate buffer. Hence, the final concentrations of AZM in each one of the reaction mixtures were ranged from 8 to $48 \mu \mathrm{g} / \mathrm{ml}$. The corresponding control solutions were also prepared using an emulsion without drug and pH 7.4 phosphate buffer. Similarly, reference standard solutions were made by dissolving $100 \mathrm{mg}$ of diclofenac sodium in $50 \mathrm{ml}$ of $\mathrm{pH} 7.4$ phosphate buffer and all other steps were also followed to get the final concentration of diclofenac in each one of the reaction mixtures ranging from 8 to $48 \mu \mathrm{g} / \mathrm{ml}$. All the reaction mixtures were incubated at $37^{\circ} \mathrm{C} \pm 2^{\circ} \mathrm{C}$ in an incubator (NSW Ltd, New Delhi, India) for 15 min followed by heating to $70^{\circ} \mathrm{C}$ for $5 \mathrm{~min}$ in a water bath. The absorbance for all the reaction mixtures was measured at $660 \mathrm{~nm}$ in a spectrophotometer (SHIMADZU UV-1800, Japan). The percentage inhibition of protein denaturation was calculated using the following formula:

$\%$ inhibition $=100\left[\frac{\mathrm{Vt}}{\mathrm{Vc}}-1\right]$

Where, $\mathrm{Vt}=$ absorbance of test sample and $\mathrm{Vc}=$ absorbance of control.

Fifty percent inhibition $\left(\mathrm{IC}_{50}\right)$ values were determined for the AZM-loaded emulsion and diclofenac-containing phosphate buffer solution. The drug concentration for $50 \%$ inhibition $\left(\mathrm{IC}_{50}\right)$ was determined by plotting percentage inhibition with respect to control against treatment concentration.

\section{In Vitro Antimicrobial Activity}

The gram-negative facultative anaerobic bacterial strain of $E$. coli (MTCC No. 3221) was obtained from the Institute of Microbial technology, Chandigarh, Punjab, India. The bacterial strain which was obtained in lyophilized forms was further activated according to their manufacturer's protocol. At first, their stock samples that contained $20 \% w / w$ glycerin were prepared from activated bacteria and kept at a freezer for further uses. The activated $E$. coli was cultured in MacConkey broth incubated for $24 \mathrm{~h}$ at $37^{\circ} \mathrm{C}$ in anaerobic conditions. The antibacterial activity of the negative and positive controls, AZM $(250 \mu \mathrm{g})$ solution, and macroemulsion with AZM $(250 \mu \mathrm{g})$ was evaluated using agar-well diffusion method according to the standards approved by the National Committee for Clinical Laboratory Standards (20). Bacterial inoculums treated with macroemulsion without AZM and treated with respective mediums only were applied as negative controls. Two stock solutions (AZM powder and AZM-loaded macroemulsion) were prepared in phosphate buffer solution of $\mathrm{pH}$ 7.4. After suitable dilution of these two stock solutions with the same buffer solution of $\mathrm{pH} 7.4,100 \mu \mathrm{l}$ from each solutions containing about or equivalent to $250 \mu \mathrm{g}$ of $\mathrm{AZM}$ was used as test samples.

In the agar-well diffusion method, firstly, an appropriate amount of prepared inoculum $(1 \mathrm{ml}$ of the cell suspension containing $10^{6}$ to $10^{7} \mathrm{CFU} / \mathrm{ml}$, approximately) of each bacterium (E. coli) was transferred into the medium. Wells with 8$\mathrm{mm}$ diameters were punched on the surface of agar media using a sterile cork borer. Aliquots of $100 \mu \mathrm{l}$ of each samples (negative and positive controls, AZM $(250 \mu \mathrm{g})$ solution, and macroemulsion with AZM $(250 \mu \mathrm{g}))$ were transferred into the wells. After incubation at $37^{\circ} \mathrm{C}$ for $30 \mathrm{~min}$, the diameter (in millimeter) of growth inhibition zones around the wells were carefully measured using a caliper (Mitutoyo, Japan) with a precision of at least $0.1 \mathrm{~mm}$.

\section{Statistical Analysis}

The mean and standard deviation of measurements were computed. All statistical analysis was performed using GraphPad Prism software (version 5.0; GraphPad Software, La Jolla, CA). Continuous variables were analyzed using an unpaired two-tailed Student's $t$ test and/or one-way analysis of variance (ANOVA) followed by Tukey post-test comparisons. The Kruskal-Wallis test with the Dunn multiple comparison test was used to evaluate differences in medians for data with a non-parametric distribution. Difference was considered significant when $p<0.05$ for all experiments with an exception of in vitro antimicrobial activity where the $p$ values of $<0.01$ were considered significant.

\section{RESULTS}

\section{Screening of Polysorbate (Tween)}

Polysorbates are available in both liquid and solid forms depending on their grades that are being segregated based on the number of oxyethylene units attached (21). Whereas polysorbate grades $20-60,80$, and 120 are yellow oily liquid at $25^{\circ} \mathrm{C}$, grades $61-65$ look tan solid and grades $81-85$ appear amber-colored liquid. Among the different liquid and solid grades of polysorbates tested, polysorbate 20 (Tween 20) in conjunction with chitosan allowed the formation of a mono- or multilayered emulsifier film around the dispersed oil droplets, and therefore, this combination was selected as emulsifying agent to design o/w macroemulsion. Moreover, preliminary screening experiments indicate that using below $1.5 \mathrm{~g}$ of polysorbate 20 and macroemulsion made without chitosan always showed a tendency to form coalescence of dispersed oil droplets and thus leads to the breakdown of o/w macroemulsion.

\section{Physicochemical Characteristics of Macroemulsion}

Table I shows the physicochemical characteristics (mean droplet diameter, zeta potential, and drug entrapment efficiency) of o/w macroemulsion with or without AZM. Although no measurement was made to determine the mean droplet diameter value of the macroemulsion prepared without AZM, the macroemulsion made with AZM exhibited the mean diameter value of $52.40 \pm 1.55 \mu \mathrm{m}$ with a polydispersity of 0.899 and presented a normal droplet size distribution curve 
Table I. Physicochemical Characteristics of Azithromycin-Loaded Oil-in-Water Macroemulsion

\begin{tabular}{llcl}
\hline Formulation & $\begin{array}{c}\text { Mean droplet diameter } \\
d_{(0.5)}(\mu \mathrm{m} \pm \mathrm{SD}, n=3)\end{array}$ & $\begin{array}{r}\text { Zeta potential } \\
(\mathrm{mV} \pm \mathrm{SD}, n=3)\end{array}$ & $\begin{array}{c}\text { Drug entrapment } \\
\text { efficiency }(\%)\end{array}$ \\
\hline o/w macroemulsion without AZM & $\mathrm{ND}$ & $-2.60 \pm 0.75$ & $\mathrm{NA}$ \\
o/w macroemulsion with AZM & $52.40 \pm 1.55$ & $+6.52 \pm 0.96$ & $91.54 \pm 5.03$ \\
\hline
\end{tabular}

$N D$ not determined, $N A$ not applicable, $S D$ standard deviation, $A Z M$ azithromycin, $o / w$ oil-in-water

(Fig. 1). In addition, TEM images (Fig. 2) illustrate that mixing of oil and water phases using the mechanical stirrer followed by the sonicator resulted in forming homogeneously dispersed macroemulsion. The data presented in Table I also shows that the zeta potential of $\mathrm{o} / \mathrm{w}$ macroemulsion was changed depending on the presence and absence of AZM inside it. It should be noted that though polycationic polysaccharide biopolymer (chitosan) was included as one of the emulsifying agents to stabilize the $\mathrm{o} / \mathrm{w}$ macroemulsion, the macroemulsion exhibited a negative zeta potential value $(-2.16 \pm 0.75 \mathrm{mV})$. On the other hand, upon addition of AZM into the emulsion, a reversal in the zeta potential value was noticed $(+6.52 \pm 0.96 \mathrm{mV})$. The drug entrapment efficiency of AZM-loaded macroemulsion was found to be $91.54 \% \pm 5.03 \%$.

\section{In Vitro Dissolution}

Figure 3 depicts the actual amount of AZM released from macroemulsion in DDW over 20-min time as a function of increasing dilution ratio. At $1 \mathrm{~min}$ post-dissolution time period, the amount of drug released from 1:5 dilution ratio was found to be $1.92 \pm 0.06 \mathrm{mg}$ followed by $1.08 \pm 0.06$ and $0.39 \pm$ $0.01 \mathrm{mg}$, respectively, when the dilution ratios were kept at 1:10 and 1:40. The Student's $t$ test showed a statistical difference in the amount of AZM released observed for these three different dilution ratios studied. At 5, 10, 15, and 20 min postdissolution time periods, a slight but steady decrease in the amount of drug released at all of the studied dilution ratios was noticed.

\section{Thermodegradation Study}

Figure 4 depicts the thermodegradation behavior of AZM-loaded macroemulsion in three different storage conditions. It should be added that keeping the 10-ml AZM solution $(2 \mathrm{mg} / \mathrm{ml})$ in $\mathrm{pH} 7.4$ phosphate buffer at all the three studied storage conditions led to the formation of drug precipitation at the bottom of the vials. In contrast, the macroemulsion allowed the AZM leakage from the inner oil phase or the oil/water interface of the emulsion that depended on the storage conditions used. The autoclave condition showed the drug leakage percentage value of $0.972 \pm 0.02$ followed by hot air oven with the drug leakage percentage value of $1.46 \pm 0.72$, and only the drug leakage percentage value of $1.18 \pm 0.54$ was noticed for room temperature.

\section{RBC Breakdown Study}

At a similar concentration of $100 \mu \mathrm{g}$ of AZM, the free drug induced $99.68 \% \pm 0.05 \%$ hemolysis while the blank o/w macroemulsion and AZM-loaded macroemulsion showed only the RBC destruction in the range of $58.35 \pm 2.72 \%-64.00 \pm$ $4.12 \%$ (Fig. 5) following incubation for $30 \mathrm{~min}$. According to Student's $t$-test, no significant difference ( $p$ value at 0.05 ) was noticed in the percentage hemolysis values shown by macroemulsion with or without AZM. However, there was a significant difference between the hemolysis percentage values obtained by free drug and macroemulsion with or without AZM.

\section{In Vitro Antimicrobial Activity}

Table II shows zone inhibition diameter values obtained for medium only-treated, AZM solution, AZM-loaded macroemulsion, and macroemulsion without AZM following the incubation time of $30 \mathrm{~min}$ with $E$. coli. The AZM solution showed a zone inhibition diameter value of $5 \mathrm{~mm}$. However, the macroemulsion with AZM and macroemulsion without AZM exhibited the zone inhibition diameter values of 4 and $3.4 \mathrm{~mm}$, respectively. The two negative controls tested produced only minimal or no zone inhibition diameter values.

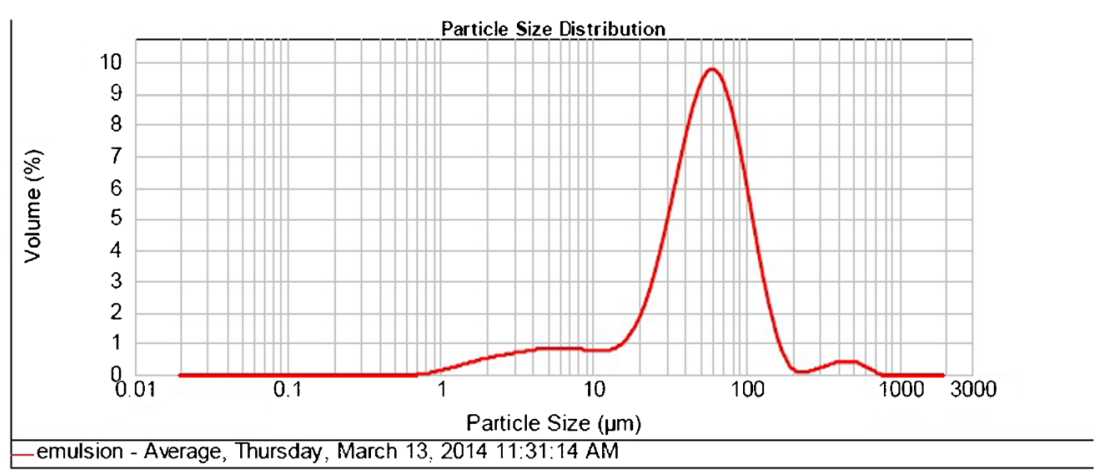

Fig. 1. Distribution of (dispersed oil) droplet size of azithromycin (AZM)-loaded oil-in-water macroemulsion analyzed utilizing a Malvern Mastersizer 

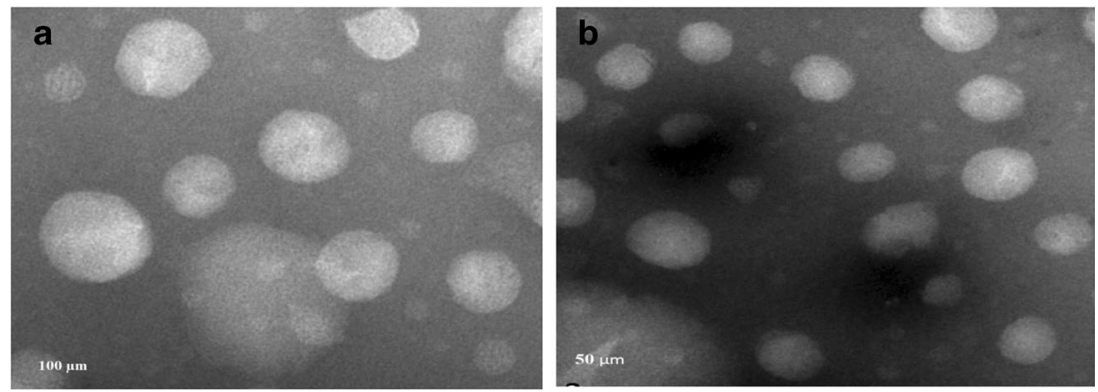

Fig. 2. Transmission electron microscopic images, following negative staining with sodium phosphotungstate, showing the population droplet size of azithromycin (AZM)-loaded emulsion immediately after mixing of oil and water phases with mild constant mechanical stirring (a) and after ultrasonication (b)

\section{In Vitro Anti-inflammatory Studies}

Figure 6 shows the percentage inhibition values for the protein (albumin) denaturation phenomenon obtained with AZM-loaded macroemulsion (test) and diclofenac sodium solution (reference). When looking at the bar graphs individually, it can be concluded that both the test and reference produced the percentage inhibition values for the protein denaturation phenomenon that was concentration-dependent $(8,16,32$, and $40 \mu \mathrm{g} / \mathrm{ml})$. Both the test and reference exhibited the $\mathrm{IC}_{50}$ value at or around the same concentration level $(\sim 16 \mu \mathrm{g} / \mathrm{ml})$. From Fig. 6 , it is evident that there was an occurrence of two different trends in the percentage inhibition values for the protein denaturation phenomenon, i.e., before $\mathrm{IC}_{50}$ and after $\mathrm{IC}_{50}$. Before $\mathrm{IC}_{50}$, the AZM-loaded macroemulsion possessed the percentage inhibition value at $8 \mu \mathrm{g} / \mathrm{ml}$ concentration level $(44.96 \% \pm 1.25 \%)$ for the protein denaturation that was higher than the percentage inhibition value at the same concentration level $(10.42 \% \pm 2.37 \%)$ for the protein denaturation obtained with diclofenac sodium reference solution. But after $\mathrm{IC}_{50}$, there was a change in the trend of percentage inhibition values for the protein denaturation obtained with test and reference. At $32 \mu \mathrm{g} / \mathrm{ml}$, the percentage inhibition values for the protein denaturation phenomenon observed with test and reference were $54.65 \% \pm 3.15 \%$ and $72.51 \% \pm 1.08 \%$, respectively. Similarly, $86.06 \% \pm 0.96 \%$ and $90.04 \% \pm 2.95 \%$ inhibition values for the protein denaturation were observed, respectively, with test and reference at $40 \mu \mathrm{g} / \mathrm{ml}$.

\section{DISCUSSION}

The skin at times is afflicted with a variety of inflammatory and non-inflammatory disorders. One such disorder is acne, a common disease characterized by various types of lesions. The lesions associated with acne are usually categorized as either non-inflammatory or inflammatory. While the non-inflammatory lesions include comedones, the inflammatory lesion consists of pustule, papule, nodule, or cyst depending on the depth in the dermis and degree of inflammation.

Azithromycin (AZM), a broad-spectrum azalide antibiotic, has been administered successfully through oral, topical, and intravenous (iv) routes in order to treat gram-negative, gram-positive, and atypical infections of the ear, eye, skin, and upper respiratory tract (22). In addition, several scientific articles have published studies establishing the efficacy of azithromycin in treating inflammatory lesions (papules and pustules) of acne (23), and thus, the AZM is rated as a

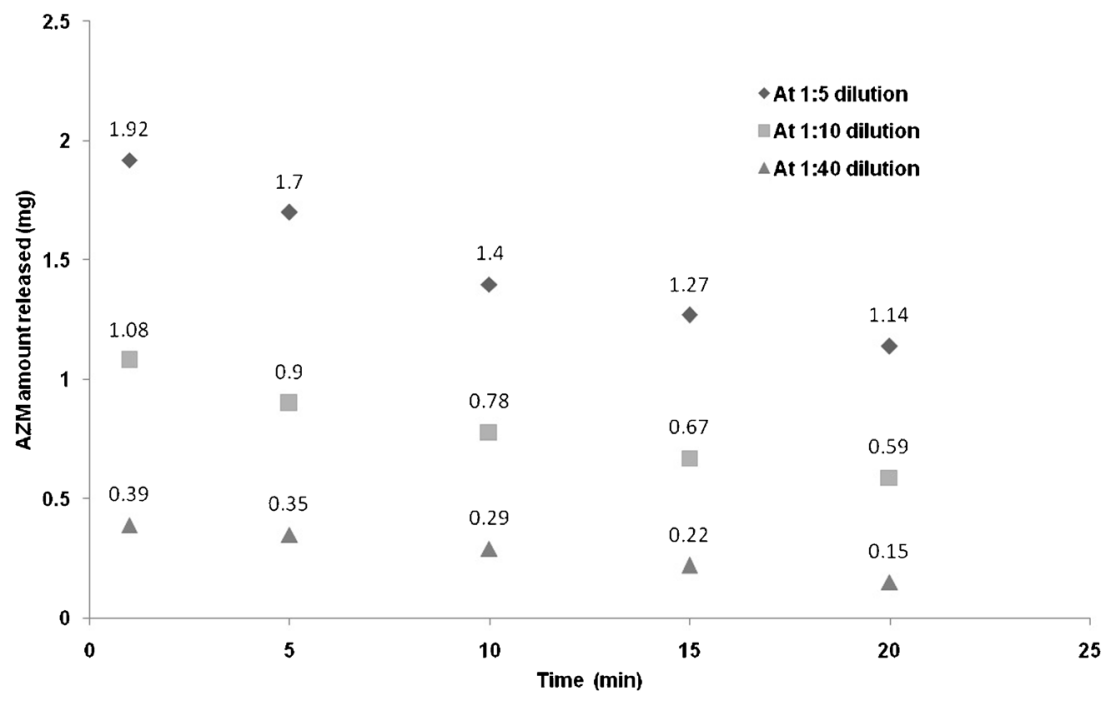

Fig. 3. Amount of AZM released from oil-in-water macroemulsion in double distilled water over 20-min dissolution time period as a function of increasing dilution ratio 


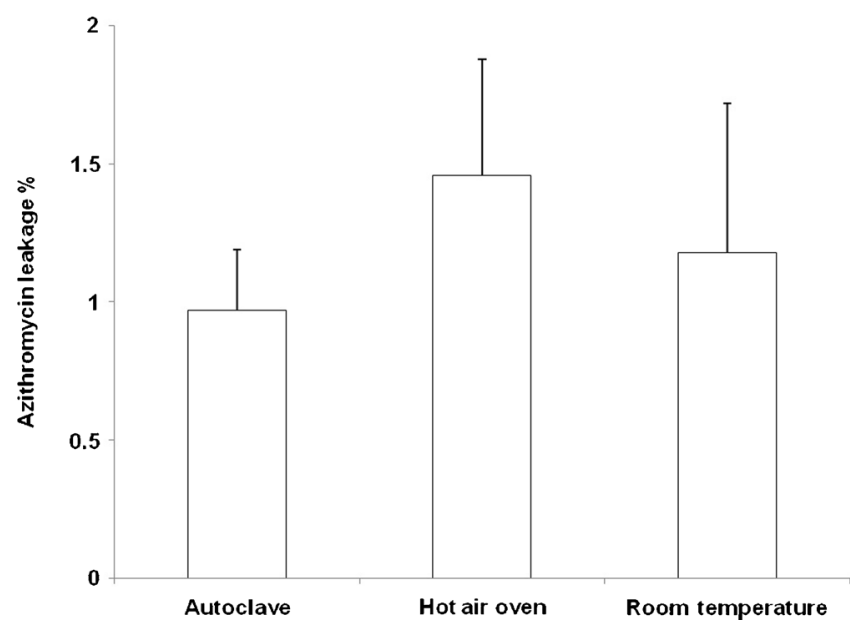

Fig. 4. Azithromycin (AZM) leakage percentage observed following the storage of AZM-loaded oil-in-water macroemulsion at three different storage conditions

mediocre treatment for acne. Moreover, a recent patent by Dow et al. (4) disclosed that following low-dose (sub-antibiotic dose level) systemic administration, the AZM retains its antiinflammatory activity and is therefore effective in treating especially inflammatory lesions (papules and pustules) of acne and other skin disorders while showing virtually no or minimal unwanted antibiotic side effects such as abdominal cramping, nausea, vomiting, diarrhea, or vaginitis. In addition, at each low-dose systemic administration of AZM, the plasma concentration never reached the minimum inhibitory concentration (MIC) of $150 \mathrm{ng} / \mathrm{ml}$ against $P$. acnes and thus minimizes the serious problem of establishing drug-resistant populations of bacteria. To treat the inflammations of the skin, it would be a better idea to develop a formulation which could be applied topically onto the inflamed areas of the skin. However, developing an aqueous-based topical formulation for AZM to manage the symptoms of acne is limited partly due to its low water solubility at neutral $\mathrm{pH}(0.003 \mathrm{mg} / \mathrm{ml})(24)$. Nevertheless a $1 \%$ aqueous solution of AZM can always lead to the formation of its major degradant product, decladinosyl azithromycin

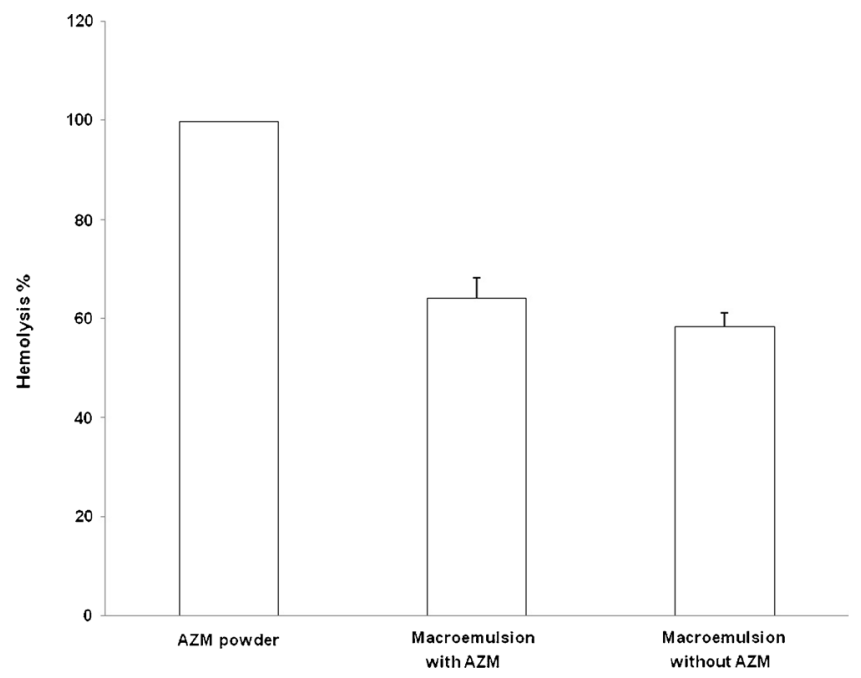

Fig. 5. Percentage hemolysis values obtained with azithromycin (AZM) powder and oil-in-water macroemulsion with or without AZM
(DES), and thus prevents the long-term therapeutic use of the aqueous-based solution (25).

When compared to the other already reported different AZM-containing solutions and suspensions, the o/w emulsion itself would offer better formulation or drug stability as the AZM is expected to entrap into either oil phase of the emulsion or $\mathrm{o} / \mathrm{w}$ interface of the emulsion. Keeping into consideration the upcoming issues like the bio- and immune-toxicity problems associated with the use of inorganic- and organicbased nanomedicines, the current investigation, however, deals with the potential of o/w macroemulsion rather than nanosized emulsion for topical application onto the skin to manage acne conditions. The previously screened castor and coconut oil combination to make the o/w nanosized emulsion was simply chosen to prepare the o/w macroemulsion (13). The chitosan and Tween 20 emulgator combination was selected for the following two purposes: (1) to prepare the o/w macroemulsion having the inherent antimicrobial activity and (2) to incorporate the AZM into the oil droplets or oil-water interface of the macroemulsion. Furthermore, the developed macroemulsion showed the viscosity and $\mathrm{pH}$ values of $1.5 \mathrm{cps}$ and 6.8-7.2, respectively, close to the viscosity and $\mathrm{pH}$ values of water or other normal physiological fluids. This indicates the suitability of the macroemulsion for topical application onto the skin.

Although the mean droplet diameter of the macroemulsion prepared without the addition of AZM was not determined, the mean droplet diameter of the AZM-loaded macroemulsion was found to be $52.40 \pm 1.55 \mu \mathrm{m}$ (Table I). It should be reasonably understood that the macroemulsion without AZM might also possessed the mean droplet diameter value similar to the value observed with AZM-loaded macroemulsion. However, a very surprising result was noticed by seeing the zeta potential values of the macroemulsion with or without AZM. The macroemulsion without AZM did show the zeta potential value in negative side $(-2.60 \pm 0.75 \mathrm{mV})$ while the AZM-loaded macroemulsion possessed the zeta potential value that was in positive side $(+6.52 \pm$ $0.96 \mathrm{mV})$. It indicates that there was a reversal in zeta potential value from negative to positive side when $100 \mathrm{mg}$ of AZM was incorporated into the macroemulsion. It should be noted that the macroemulsion without AZM was prepared based on the emulgator combination that consisted of $50 \mathrm{mg}$ of chitosan and $1500 \mathrm{mg}$ of Tween 20. Naturally, the presence of chitosan in the emulgator combination should confer/provide a positive charge to the macroemulsion as the chitosan is polycationic biopolymer having $\mathrm{pKa}$ values of $\sim 6.5$, which can become protonated in weakly acidic conditions. It is this polycationic character that confers chitosan's antimicrobial properties, which favors interaction with negatively charged microbial cell walls and cytoplasmic membranes. This electrostatic interaction between protonated chitosan and microbial cell walls results in decreased osmotic stability, membrane disruption and eventual leakage of intracellular elements (26). Since the macroemulsion without AZM showed a negative zeta potential value, it is clear that the formation of protonated chitosan is very low. But the question remains how the macroemulsion without AZM was able to be physically stable at room temperature. It should be remembered that there are two stabilizing forces acting inside the $\mathrm{o} / \mathrm{w}$ emulsion system to disperse/stabilize the oil droplets in the water namely, cationization and steric hindrance. Indeed, the Tween 20 is known for its steric hindrance effect and thus it basically stabilizes the o/w macroemulsion. By weight amount comparison, the ratio 
Table II. Zone Inhibition Diameter Values Obtained for Medium-Only Treated, Azithromycin Solution, AZM-Loaded Macroemulsion, and Macroemulsion Without AZM Following an Incubation Time Period of 30 min With Escherichia coli

\begin{tabular}{lcccc}
\hline Incubation time $(\mathrm{min})$ & \multicolumn{3}{l}{ Zone inhibition diameter $(\mathrm{mm})$ values obtained with } \\
\cline { 2 - 4 } & Medium only & AZM solution & AZM-loaded macroemulsion & Macroemulsion without AZM \\
\hline 30 & 0.0 & 5.0 & 4.0 & 3.4 \\
\hline
\end{tabular}

$A Z M$ azithromycin

between chitosan and Tween 20 (as the current emulgator combination) is 1:30. So, naturally, the o/w macroemulsion without AZM was found to be stable because of the steric hindrance effect produced by the Tween 20, which, in turn, prevented oil droplet coalescence upon random collisions. This explanation seems to be a plausible reason why the o/w macroemulsion having the negative zeta potential value was able to maintain its physical stability at the room temperature condition. However, a long-term stability study is underway in our laboratory to see the shelf life of the o/w macroemulsion having chitosan and Tween 20 emulgator combination.

When looking for the reason why the chitosan (and Tween 20-)-based macroemulsion exhibited a negative zeta potential value, the dispersed oil droplets are basically stabilized by a mono- or multimolecular emulgator film comprising of an intercalated two different emulgator molecules. In the current macroemulsion, such type of intercalation networking occurs between the two emulgator molecules by engulfing of smaller amount emulgator molecules (chitosan) with the high amount emulgator molecules (Tween 20). In other words, the direct exposure of chitosan to surrounding water medium is somewhat masked by the Tween 20 which in turn prevented the protonated chitosan form to occur and therefore no positive charge is conferred over the emulsified oil droplets of the macroemulsion.

On the other hand, the AZM-loaded o/w macroemulsion was also found to be stable at room temperature condition and this emulsion possessed the positive zeta potential value of
$+6.52 \pm 0.96 \mathrm{mV}$. The addition of a fixed amount $(100 \mathrm{mg})$ of basic drug like AZM into the macroemulsion should contribute a positive charge to the $\mathrm{o} / \mathrm{w}$ interface of the emulsion by intercalating into the emulgator combination network. This is why the reversal in zeta potential value was noticed upon addition of AZM into the macroemulsion. A similar reversal in zeta potential value of o/w nanosized emulsion was noticed after inclusion of either AZM or cyclosporine A $(14,27)$. Collectively, the stability of macroemulsion without AZM was primarily due to the steric hindrance effect of Tween 20, whereas for AZM-loaded macroemulsion, the physical stability of the macroemulsion was because of positive zeta potential value conferred by the AZM along with the Tween 20's steric hindrance effect.

Keeping the AZM molecule in phosphate buffer solution ( $\mathrm{pH}$ 7.4) always led to the precipitation of the drug molecules in all of the studied three different (stipulated) storage conditions. According to Bowman et al. (25), the AZM molecule is prone to undergo hydrolytic degradation in aqueous-based solution that lead to the formation of its major degradant product, DES. It is our belief that the total precipitation of AZM molecule in $\mathrm{pH} 7.4$ phosphate buffer should be corroborated with the complete drug degradation product formation. On the other hand, the AZM molecule after its incorporation into chitosan- and PEG-based o/w macroemulsion exhibited the drug leakage percentage value of $0.972 \pm 0.02$ in the autoclave storage condition followed by $1.46 \% \pm 0.72 \%$ drug leakage in hot air oven and $1.18 \% \pm 0.54 \%$ in room temperature

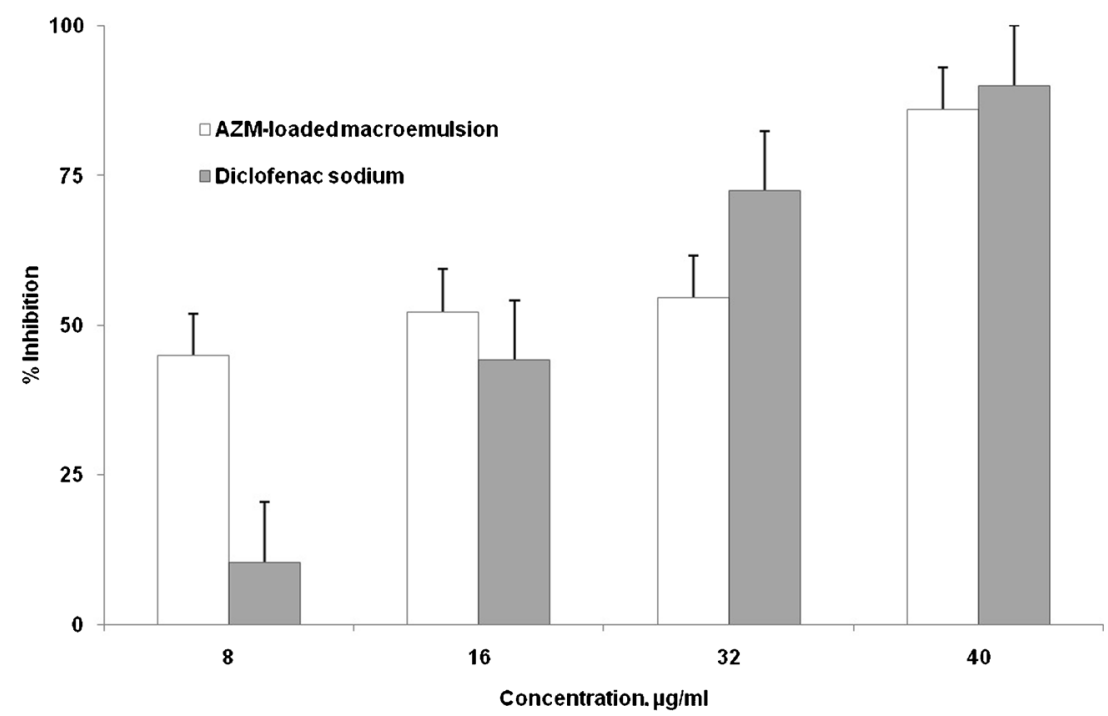

Fig. 6. Percentage inhibition values for the protein (albumin) denaturation phenomenon obtained with AZM-loaded macroemulsion (test) and diclofenac sodium solution (reference) 
conditions (Fig. 4). In our previous experiment, the AZM molecule was incorporated into PEG-based microparticles wherein about $13 \%$ drug leakage was noticed after storing of the microparticles in autoclave conditions followed by $8.65 \%$ $\pm 0.72 \%$ drug leakage in hot air oven and $4.15 \% \pm 1.54 \%$ in room temperature conditions (28). Switching from microparticles to macroemulsion, the AZM molecule appears to be more tightly bound to the inner castor oil core or oil-inwater interface of the macroemulsion. Therefore, the chitosan- and PEG-based o/w macroemulsion shows a lesser AZM leakage percentage value than the drug leakage percentage value observed with PEG-based microparticles at all of the studied three different storage conditions. Furthermore, the observed low drug leakage percentage values following even in the autoclave storage condition of chitosan- and PEGbased $\mathrm{o} / \mathrm{w}$ macroemulsion (when compared to the precipitation of drug in phosphate buffer solution of $\mathrm{pH}$ 7.4) could provide an impetus to work further with the macroemulsion.

A very interesting insight found in the RBC breakdown study wherein the free drug produced almost $100 \%$ hemolysis while macroemulsion with or without AZM showed the RBC destruction with an average value of about $60 \%$ (Fig. 5) following $30 \mathrm{~min}$ post-incubation time period. Significant amount of AZM, like other hemolytic hydrophobic/lipophilic compounds, is probably incorporated inside the oil droplets of the macroemulsion. Consequently, AZM has only a limited direct contact with the tested blood cells and is not easily partitioned from oil phase to water phase of the macroemulsion, resulting in the loss of its hemolytic activity. Such a mechanism has been suggested for other lytic agents (29). Similar observations were also seen previously for AZM when incorporating it into the non-phospholipid-based cationic oil-inwater nanosized emulsion (13) or/and into PEG-based microparticles (28).

When looking at in vitro dissolution results, the AZM-loaded macroemulsion were shown retardation in drug release depending on the dilution ratios tested (Fig. 3). Upon keeping the drug-loaded macroemulsion in DDW at three different dilution ratios, the chitosan and Tween 20 mono- or multimolecular emulgator film which was formed at the vicinity of dispersed oil droplets was destabilized by dissolution medium (water) leading to the complete collapse in the emulsion structure. That is why the AZM was released from macroemulsion at $1 \mathrm{~min}$ post-dissolution time period at all of the studied dilution ratios. The DDW was selected as dissolution medium in the current investigation with an adamant belief that the macroemulsion would encounter the similar environment following its topical skin application over the inflamed area produced due to acne skin disorders. Furthermore, being a topically applicable formulation, the macroemulsion might be mixed with a few drops of water before its application onto the affected skin area by the patient. Hence, to see this possible dilution circumstance before its topical application onto the skin, the in vitro dissolution of drugloaded macroemulsion in DDW at three different dilution ratios was tested. However, a question might arise regarding the influence of size of $\mathrm{o} / \mathrm{w}$ emulsion (whether nano or macro) to prevent inflammation following topical application onto the skin areas that contained the inflammatory lesions of acne. Some reports point out that it would be preferable to have a particle size range in submicron or even nanometer level for better therapeutic activity following topical application onto skin. Another question that might arise after looking at this work is that whether or not any synergistic antimicrobial activity will be observed following the antibiotic molecule (AZM) incorporation into the $\mathrm{o} / \mathrm{w}$ macroemulsion having inherent antimicrobial activity. To substantiate this important question, macroemulsion with or without AZM was tested with the model microorganism (E. coli). At $30 \mathrm{~min}$ post-incubation time with E. coli, a slight increment in the zone inhibition diameter value was observed for AZM-loaded macroemulsion in comparison to the zone inhibition diameter value of macroemulsion without AZM ( 4 vs. $3.4 \mathrm{~mm}$, Table II). A pilot study is going on at our laboratory to see the synergistic antimicrobial activity of AZM-loaded macroemulsion against the real microorganism using $P$. acnes.

Since there are certain limitations to use laboratory animals to induce acne and its associated inflammations, the anti-inflammatory potential of AZM-loaded coarse emulsion should be investigated in an indirect way. Hence, in the current investigation, the protein denaturation bioassay was selected for the in vitro anti-inflammatory assessment of drug-loaded macroemulsion. From the literature survey, it was found that production of auto-antigens in certain inflammatory or arthritis diseases may be due to the denaturation of proteins in vivo $(30,31)$. In a previous report, Chandra et al. (19) also demonstrated that the prevention of protein denaturation by medicinal agents under an in vitro experimental condition is an indication of anti-inflammatory effect, and therefore, this test would be worthwhile to use routinely for the preliminary screening of anti-inflammatory effect during the drug development process. Using this reported fact, higher percent inhibition value at a lowest possible concentration level would be the best formulation. When looking at the bar graphs individually (Fig. 6), it can be concluded that both the test and reference produced the percentage inhibition values for the protein denaturation phenomenon that was concentration-dependent $(8,16,32$, and $40 \mu \mathrm{g} / \mathrm{ml})$. Therefore, it can plausibly be concluded that upon topical application of AZM-loaded emulsion onto the inflamed skin surfaces produced due to Acne vulgaris, an increased anti-inflammatory effect is likely to occur.

\section{CONCLUSION}

The AZM-loaded o/w macroemulsion prepared based on chitosan and Tween-20 emulgator combination showed physical stability, reduced drug thermodegradation, diminished RBC breakdown, and sustained antimicrobial activity in comparison to AZM solution counterpart. Furthermore, improved in vitro anti-inflammatory property was also observed compared to control diclofenac sodium solution. The observed overall enhanced performances of AZM after its incorporation into $\mathrm{o} / \mathrm{w}$ macroemulsion when compared to AZM solution should further be utilized for the judicious management of multifactorial acne conditions. However, thorough in vivo studies need to be conducted in real acne skin conditions. 


\section{ACKNOWLEDGMENTS}

The encouragement and support given by the management of Lovely Professional University, India, to perform this research work is acknowledged.

Conflict of interest The authors declare that they have no competing interests.

\section{REFERENCES}

1. Nakatsuji T, Kao MC, Fang JY, Zouboulis CC, Zhang L, Gallo $\mathrm{RL}$, et al. Antimicrobial property of lauric acid against Propionibacterium acnes: its therapeutic potential for inflammatory acne vulgaris. J Invest Dermatol. 2009;129:2480-8.

2. Riddle CC, Amin K, Schweiger ES. Review of azithromycin for the treatment of acne vulgaris. Cosmetic Dermatol. 2007;20(5):299302.

3. Webster GF. The pathophysiology of acne. Cutis. 2005;76(2 suppl):4-7.

4. Dow GJ, Chaudhuri B, Osborne DW, Calvarese B. Azithromycin for treatment of other skin disorders. US Patent 8,143,227 B2, 2012.

5. Kawashima M, Hashimoto H, Sáenz ABA, Ono M, Yamada M. Is benzoyl peroxide $3 \%$ topical gel effective and safe in the treatment of acne vulgaris in Japanese patients? A multicenter, randomized, double-blind, vehicle-controlled, parallel-group study. J Dermatol. 2014;41:795-801.

6. Date AA, Naik B, Nagarsenker MS. Novel drug delivery systems: potential in improving topical delivery of antiacne agents. Skin Pharmacol Physiol. 2006;19:2-16.

7. Lin CH, Fang YP, Al-Suwayeh SA, Yang AY, Fang JY. Percutaneous absorption and antibacterial activities of lipid nanocarriers loaded with dual drugs for acne treatment. Biol Pharm Bull. 2013;36(2):276-86.

8. Hwang YY, Ramalingam K, Bienek DR, Lee V, You T, Alvarez R. Antimicrobial activity of nanoemulsion in combination with cetylpyridinium chloride in multidrug-resistant Acinetobacter baumannii. Antimicrob Agents Chemother. 2013;57(8):3568-75.

9. Karthikeyan R, Amaechi BT, Rawls HR, Lee VA. Antimicrobial activity of nanoemulsion on cariogenic Streptococcus mutans. Arch Oral Biol. 2011;56:437-45.

10. Hemmila MR, Mattar A, Taddonio MA, Arbabi S, Hamouda T, Ward PA, et al. Topical nanoemulsion therapy reduces bacterial wound infection and inflammation after burn injury. Surgery. 2010;148:499-509.

11. Hamouda T, Myc A, Donovan B, Shih AY, Reuter JD, Baker Jr JR. A novel surfactant nanoemulsion with a unique non-irritant topical antimicrobial activity against bacteria, enveloped viruses and fungi. Microbiol Res. 2001;156:1-7.

12. Hamouda T, Baker Jr JR. Antimicrobial mechanism of action of surfactant lipid preparations in enteric Gram-negative bacilli. J Appl Microbiol. 2000;89:397-403.

13. Tamilvanan S, Khanum R, Senthilkumar SR, Muthuraman M, Rajasekharan T. Studies on ocular and parenteral application potentials of azithromycin-loaded anionic, cationic and neutralcharged emulsions. Curr Drug Deliv. 2013;10:572-86.
14. Liu Y, Lin X, Tang X. Lipid emulsions as a potential delivery system for ocular use of azithromycin. Drug Dev Ind Pharm. 2009;35(7):887-96.

15. Wang LX, He HB, Tang X, Shao RY, Chen DW. A less irritant norcantharidin lipid microspheres: formulation and drug distribution. Int J Pharm. 2006;323:161-7.

16. Ferezou J, Nguyen TL, Leray C, Hajri T, Frey A, Cabaret Y, et al. Lipid composition and structure of commercial parenteral emulsions. Biochem Biophys Acta. 1994;1213:149-58.

17. Tamilvanan S, Kumar BA. Influence of acetazolamide loading on the (in vitro) performances of non-phospholipid-based cationic nanosized emulsion in comparison with phospholipid-based anionic and neutral-charged nanosized emulsions. Drug Dev Ind Pharm. 2011;37:1003-15.

18. Jaromin A, Zarnowski R, Kozubek A. Emulsions of oil from Adenanthera pavonina $\mathrm{L}$. seeds and their protective effects. Cell Mol Biol Lett. 2006;11:438-48.

19. Chandra S, Chatterjee P, Dey P, Sanjib S. Evaluation of in vitro anti-inflammatory activity of coffee against the denaturation of protein. Asian Pac J Trop Biomed. 2012;S178-80.

20. National Committee for Clinical Laboratory Standards. Methods for dilution antimicrobial susceptibility tests for bacteria that grow aerobically, Approved Standard M7-A5. 5th ed. Wayne, PA: NCCLS; 2000.

21. Rowe RC, Sheskey PJ, Quinn ME. Handbook of pharmaceutical excipients. 6th ed. London: Pharmaceutical Press; 2009. p. 54953.

22. Arguedas A, Soley C, Kamicker BJ, Jorgensen DM. Single-dose extended-release azithromycin versus a 10-day regimen of amoxicillin/clavulanate for the treatment of children with acute otitis media. Int J Infect Dis. 2011;15(4):e240-8.

23. Gillis RJ, Iglewski BH. Azithromycin retards Pseudomonas aeruginosa biofilm formation. J Clin Microbiol. 2004;42:5842-5.

24. Sevillano D, Alou L, Aguilar L, Echevarría O, Giménez MJ, Prieto J. Azithromycin iv pharmacodynamic parameters predicting Streptococcus pneumoniae killing in epithelial lining fluid versus serum: an in vitro pharmacodynamic simulation. J Antimicrob Chemother. 2006;57(6):1128-33.

25. Bowman LM, Si E, Pang J, Archibald R, Friedlaender M. Development of a topical polymeric mucoadhesive ocular delivery system for azithromycin. J Ocul Pharmacol Ther. 2009;25(2):133-9.

26. Friedman AJ, Phan J, Schairer DO, Champer J, Qin M, Pirouz A, et al. Antimicrobial and anti-inflammatory activity of chitosanalginate nanoparticles: a targeted therapy for cutaneous pathogens. J Investigative Dermatology. 2013;133:1231-9.

27. Tamilvanan S, Khoury K, Gilhar D, Benita S. Ocular delivery of cyclosporine A. Part 1. Design and characterization of cyclosporin A-loaded positively-charged submicron emulsion. STP Pharma Science. 2001;11(6):421-6.

28. Tamilvanan S, Kumar V, Deepak S, Ashutosh T. In vitro evaluation of polyethylene glycol-based microparticles containing azithromycin. Drug Deliv Translational Res. 2014;4:139-48.

29. Jumaa M, Müller BW. Lipid emulsions as a novel system to reduce the hemolytic activity of lytic agents: mechanism of the protective effect. Eur J Pharm Sci. 2000;9:285-90.

30. Umapathy E, Ndebia E, Meeme A, Adam B, Menziwa P, Chungag BN. An experimental evaluation of Albuca setosa aqueous extract on membrane stabilization, protein denaturation and white blood cell migration during acute inflammation. J Med Plants Res. 2010;4:789-95.

31. Opie E. On the relation of necrosis and inflammation to denaturation of proteins. J Exp Med. 1962;115:597-608. 